\title{
The Life Course Construction of Inequalities in Health and Wealth in Old Age
}

\author{
Michel Oris, Marie Baeriswyl, and Andreas Ihle
}

\subsection{Health, Wealth and the Life Course}

In this contribution we study health and wealth in old age as the outcomes of long life courses as well as crucial preconditions for the maintenance of activity and well-being. It is worth to note that all the main concepts we consider have a common history. All emerged in the late twentieth century

M. Oris $(\bowtie)$

Swiss National Centre of Competence in Research LIVES - Overcoming Vulnerability: Life Course Perspectives, University of Geneva, Geneva, Switzerland

Centre for the Interdisciplinary Study of Gerontology and Vulnerability, University of Geneva, Geneva, Switzerland

Institute of Demography and Socioeconomics, University of Geneva, Geneva, Switzerland

e-mail: michel.oris@unige.ch

\section{Baeriswyl}

Swiss National Centre of Competence in Research LIVES - Overcoming Vulnerability: Life Course Perspectives, University of Geneva, Geneva, Switzerland

Centre for the Interdisciplinary Study of Gerontology and Vulnerability, University of Geneva, Geneva, Switzerland e-mail: marie.baeriswyl@unige.ch

A. Ihle

Swiss National Centre of Competence in Research LIVES - Overcoming Vulnerability: Life Course Perspectives, University of Geneva, Geneva, Switzerland

Centre for the Interdisciplinary Study of Gerontology and Vulnerability, University of Geneva, Geneva, Switzerland

Cognitive Aging Lab, University of Geneva, Geneva, Switzerland

e-mail: andreas.ihle@unige.ch and have since known an impressive success in the scientific circles and beyond. In the 1980s, a growing discrepancy was observed between on one side the theory of disengagement, originally developed 20 years earlier to describe the retired withdrawal from social life associated with senescence and disability, and on the other side the growth of life expectancy and the improvements of the health and living conditions of the elderly (Baeriswyl 2016; Oris et al. 2017). The need for a new frame resulted in the theory of "successful aging" that since its first formulation by Rowe and Kahn (1987) became immediately highly influential. In this perspective, an appropriate lifestyle made possible to preserve good health and maintain active engagements. The approach of Paul Baltes and Margret Baltes (1991) was different since they defined the success as the capacity to self-regulate and even master the inevitable changes due to aging while maintaining a sense of self (see Bülow and Söderqvist 2014, for an in-depth comparison of the two models). Both Rowe and Kahn and the Baltes wanted to break with the dark visions of aging and with the stereotypes of elderly as passive. Both refused to see older adults as a burden for society and promoted quality of life in old age (Mendes 2013, p. 176).

As strange as it could seem today, well-being as a personal objective has not an absolute value. Collinet and Delalandre (2014) showed how wellbeing became a political objective in the second half of the twentieth century, then how well-being 
as personal self-realization has emerged in the 1990s. It immediately became a major topic. Indeed, a simple research in Google Scholar of the various spellings of wellbeing show a quasiabsence in the 1970s, a timid emergence in the 1980s, an explosion of interest and publications in the 1990s, continuing in the first decade of the twenty-first century, and still from 2010, although more slowly (Oris 2017).

The centration on the micro-individual perspective similarly explains the parallel success of the life course analysis. Although some famous publications pioneered the field, this approach really became popular, diffused among all the social sciences, from the 1980s (Settersten 2018). Typically, the life course was central in Rowe and Kahn (1987) view since they saw successful aging as constructed all along life through adequate behaviors, while for Baltes the aptitude of managing aging depended on reserves constructed across the human development (see Cullati et al. 2018). The various conceptions of active aging also explicitly consider past life trajectories as a crucial factor. ${ }^{1}$

The simultaneous chronologies of the renewal in the researches on aging and well-being and of the life course analysis popularity are not a matter of coincidence. They reflect major sociological changes, mainly the individualization theorized by Anthony Giddens (1991) as the most recent chapter in the history of the "society of individuals" (Elias 1991). A new normative figure was imposing itself, the autonomous, responsible individual, implying according to Honneth (2004, p. 463) a "promise of freedom" supporting "an ideology of de-institutionalization". Indeed, at the end of the twentieth century the neo-liberal context also played a role, but more cyclical than structural since rapidly, the emerging theories, models and approaches received severe critics. Among the most important, the first one was the implicit but strong elitism of the successful aging models which neglect social inequalities. Not everybody can afford a healthy living style or accumulate reserves (Katz 1996). Second, some

\footnotetext{
${ }^{1}$ See especially the position of the World Health Organization: https://www.who.int/ageing/en/
}

scholars denounced the discourse about prevention as a tool for "moralizing old age", imposing "virtuous" behaviors to supposedly free individuals (Oris et al. 2015, p. 217). Third, successful implies unsuccessful and a stigmatization of the "losers", guilty of inappropriate behaviors, without considering the many factors that are susceptible to affect disability in old age and are not under the individual control (Dannefer et al. 2019).

The various answers to those criticisms are foundations for this contribution. First, the appreciation of what is a good aging by the older adults themselves was studied (Bülow and Söderqvist 2014). Second, the chance to "live a life you own value" (Sen 1999, p. 285) depends of a diversity of values but also, very concretely, of the resources or reserves that are available to the aging individual who has the freedom to use them, or not. Indeed, "well-being is characterized by the capacity to actively participate in work and recreation, create meaningful relationships with others, develop a sense of autonomy and purpose in life, and to experience positive emotions" (Hatch et al. 2007, p. 187).

This is a support for "active aging", a slogan that became dominant in the early twenty-first century because powerful international organizations and most of the States have adopted this objective. However, in the continuity of the debates about successful aging, and although the WHO (2002) vision explicitly consider individual wishes and capacities, the social norm promoted by the active aging discourses, the "duty" to be active, is vividly denounced because such pressure weights disproportionately on the disadvantaged (Mendes 2013; Van Dyk 2014; SAPEA 2019). Indeed, the unequal distribution of health and wealth resources or reserves in the elderly population defines unequal capacities to manage aging, to select and practice activities that are sources of well-being (Blane et al. 2004; Jivraj and Nazroo 2014; Baeriswyl 2016). This chapter is concentrated on the life course construction of those inequalities, in health and wealth, among the older adults, from the cradle to old age. 
Although the life course perspective uses the individual as unit of analysis, this individualism is only methodological since this approach locates individual agency within structures, these structures referring to different levels - macro (time and space), meso (social network and linked lives) and micro (past experiences) (see Elder et al. 2015, for an extensive discussion of the life course principles). In the following we borrow mainly to life course sociology results on the life antecedents of the unequal distribution of wealth and health in old populations. Although less systematically, we also include insights from life course epidemiology and lifespan psychology. Our objective is to look how have been accumulated (or not) the wealth and health reserves needed to be active actor in the preservation of wellbeing. Other resources are potentially important, especially the original genetic endowment of each individual, but are beyond the scope of this contribution. Family history and social relations are also crucial but would require a full chapter. In the next sections we start with the ages of life and follow with ongoing theoretical debates before concluding.

\subsection{The Ages of Life}

In the so-called developed world, the birth cohorts who are old now in the early twenty-first century, have seen their life trajectories structured by a process of institutionalization that has been amply studied by the European scholars (Brückner and Mayer 2005; Kohli 2007; Levy and Bühlmann 2016). The development of various welfare regimes resulted in a division in three stages associated with specific roles: youth until the age at compulsory schooling or legal majority, then adulthood to enter the labor force and settle a family, until a retreat also fixed by law and that defined old age. Most of the researches on the life course construction of active aging and wellbeing in old age use this structuration of life, looking at early life conditions, then at the mediating or moderating impact of adult life.

\subsubsection{Early Life Conditions}

Early life even starts before birth. The importance of genetic is well-established in several fields, especially cognitive ability, and has an influence all across the life course (Richards and Deary 2013). However, heritability also concerns ascribed traits (like sex, skin color, ethnicity, etc.) that society can use to discriminate individuals all across their life. The medical doctor David Barker (1997) developed an influential theory about the onset of life, more precisely about foetal growth which is related to mother's alimentation. In the western epidemiological regime where deaths are concentrated in old and very old age and are largely due to degenerative diseases, a lower cellular density of organs acquired during pregnancy and the very beginning of life has long-term impact on longevity and health in old age (mainly through hypertension and coronary heart diseases). This hypothesis has been confirmed by a flow of subsequent studies (see McEniry 2013, for a systematic review). In those researches, birth prematurity and birthweight are often used as proxy. Both are clearly dependent on the parental socioeconomic position but have an influence of their own on the development of cognition in childhood (Richards and Deary 2013). The developments of Barker theory provide a direct illustration of the embeddedness of the biological, psychological and socioeconomic dimensions and the difficulty to disentangle their respective influence.

This challenge remains when we consider infancy and childhood that lifespan psychology, life course epidemiology and life course sociology all see as a critical (or sensitive) life period. Indeed, the earlier chapters of life are decisive in the formation of emotional capital, and also of the cognitive reserve that will be crucial in later life. This reserve will help, to protect from and cope with brain damage, contributing to reduce dementia development risk, delaying the onset of cognitive impairment or slowing decline (Stern 2002; Richards and Deary 2013; Ihle et al. 2015).

In the initial constitution of cognitive reserve education in young age plays an important role, 
and is highly dependent on the socioeconomic position of the children family. Galobardes et al. (2007, p. 23) have shown that a surprisingly high number of indicators of socioeconomic positions have been used in a large number of researches. The dominant perspectives are the neo-Marxist inscription in social classes and the Weberian approach of power relations and life chances. Concretely all conclude to a high probability of social reproduction with children of disadvantaged background having low educational achievements and inversely (Keister and Southgate 2012). The long-term impact of this inequality in the distribution of human capital is striking. In a country like Switzerland, in 1979, 1994 and 2011, three times consecutively a low educational level implicated a multiplication by four of the risk of old age poverty, compared to those with a tertiary diploma. The persistence of this effect is remarkable since the proportion of older adults with a low human capital decreased from 66 to 18 percent during this period, without changing the statistical relation to poverty risk.

Separately from the socioeconomic status, research has also considered the effects of adverse childhood experiences (ACE). Globally, life course research has well-established the role of non-normative events, or accidents of life. They have the potential to heavily impact individual trajectories and, in that case, to become a "turning point" in life trajectories (Oris 2017). Specifically, ACE include traumatic events experienced between ages 0 and 15 like parental death, parental mental illness, parental drinking abuse, period of hunger, property taken away, living in an orphanage (Cheval et al. 2019). For psychologists, they are proxies of the real explanations of long-term effects which could be the quality of the relationships between parents and child and between siblings, parenting styles, or attachment styles (Gale et al. 2013). For the epidemiologist Kelly-Irving and her colleagues (2013) the stress related to ACE is leading to diseases like cancer later in life. In a different perspective, Wilson et al. (2006) showed that ACE are associated with isolation in old age that explains low levels of wellbeing.
Along the same logic, the LIFETRAIL project $^{2}$ also studied "adverse childhood health experiences", which basically reflected a poor health early in life that has been shown to negatively affect functional health (disability) (McEniry 2013) and more generally the frailty syndrome (van der Linden et al. 2019). However, health issues during childhood are disproportionately associated with poor socioeconomic conditions. Both act as "The long arm of childhood" (Haas 2008) and reduce the chances for successful aging as defined by Rowe and Kahn (see Brandt et al. 2012; Cheval et al. 2018).

\subsubsection{Adult Age}

If the long-term impact of early life conditions is well-established by a flow of researches from various disciplines, the importance of adult life is more debated. Pinquart and Sorensen (2000) conducted a meta-analysis based on 205 studies which highlighted a positive relation between adult SES and subjective wellbeing in later life, but this relation was weak and more specific for men than women. The limited robustness of these findings can be explained if we consider the factors behind wellbeing, with results which appear more scattered and also more complex. Of course, it is clear that people with a high social status are better equipped to cope with hassles and critical life events (Gale et al. 2013, p. 8), and that advantaged adults tend to reach old age in better physical and cognitive states than the others (Kuh 2007). However, this pattern has not an absolute value. Using SHARE data, Van der Linden et al. (2018) have just recently shown that the onset of overall cancer in old age was more frequent among the advantaged men and women. When looking by site they found this social pattern affecting breast cancer among women. A possible explanation is the higher survival of women of high social status (Bouchardy et al. 2006) who are consequently still alive, able to be surveyed and declare a cancer episode. Another hypothesis

\footnotetext{
${ }^{2}$ https://cigev.unige.ch/recherches/research-1/ageing/ lifetrail/
} 
would refer to the historical evolution of an important behavior, smoking, usually initiated in early adulthood, which spread from men to women during the last decades (Janssen and Van Poppel 2015). Smoking has also a spatial pattern across the globe. Those elements of space and time are important in life course theories but relatively absent in studies of aging origins.

Until now, much more frequent has been the identification of mediating and moderating factors. In statistical terms, do adult life conditions capture, reduce or increase the impact of childhood conditions? It is difficult to summarize many results that are sometimes inconsistent and depend heavily on both the studied outcome and the explanatory variable which is tested. As an illustration, a systematic review of Galobardes et al. (2007) showed that stomach cancer is associated only with early life socioeconomic conditions, while childhood-SEP and adult-SEP together increase the probability of chronic health diseases. Another example is provided by Landös et al. (2018) who studied the difficulties older adults are faced with in the activities of daily living. They show that both women and men were affected by childhood socioeconomic circumstances and that adult occupation and making ends meet have a mediating effect on this relation only for men. Cheval and his colleagues (2018) studied old age physical health using muscle strength as indicator, and demonstrated that the long-term impact of early life socioeconomic conditions remains even when controlling for adult socioeconomic conditions and unhealthy behaviors, especially among women. This is largely coherent with the results of Pakpahan et al. (2017) who also used SHARELIFE data and showed that the strong relation between childhood SES and old age health is mediated by education and adult SES while there is no midlife factor able to moderate the direct impact of childhood health on old age health.

Among the potential later life modifiers, researchers have given some consideration to social mobility and its capacity to compensate for early-life disadvantages. Results are however mixed, sometimes positive, sometimes not, and even sometimes going in the unexpected negative direction (Vanhoutte and Nazroo 2016). It could be because frequency and perception of social mobility highly vary across countries, depending on their labor market and institutions (see Mayer 2004).

Like in childhood, there is also a place for events of adult life in the explanation of unequal resources in old age. Pearlin et al. (2005) rightly noted that the events that have the strongest disruptive potential are those affecting the social roles attributed to adulthood, and consequently the identity of the affected individual: developing a career on the labor market and raising a family. Those events can be related by chains of adversity or spillover effects across life domains (Spini et al. 2017; Bernardi et al. 2019). Ben-Shlomo and Kuh (2002, p. 285) gives the example of a job loss leading to tensions in the family leading to physical abuse leading to divorce. They insist that the links have a probabilistic and not a deterministic nature. And that the final result, divorce, can result from the accumulation (additive effect) or only of the final episode which is physical abuse in this example (trigger effect). Pearlin and his colleagues (2005) and Oris (2017) insist on the characteristics of the events that can be traumatic, non-normative (typically a transition occurring before the proper social age, like a teenager pregnancy) and undesirable, and/or unexpected. In all the cases, both exposures and capacity to cope with those risks are unequally distributed among the social classes (Lantz et al. 2005).

\subsection{Life Course Processes, Life Course Theories}

\subsubsection{Accumulation or Continuity, Selection or Cause?}

In this confuse landscape theories are needed. When adult-SEP captures the impact of childhood circumstances it could simply reflect the continuity of condition across the life course. Life course sociologists see the school system as a "phasing institution": "By sequencing life courses and by 
regulating the ways and extent to which individuals can acquire life-course relevant resources an can use them in their biographical projects (...), phasing institutions have a particularly strong impact on life courses" (Levy and Bühlmann 2016, p. 34). Brückner and Mayer (2005, p. 29) underlined: "the expansion of secondary and tertiary education and training created career paths within and between educational institutions. It also moved young adults to labor market entry positions at different levels, thereby minimizing or decreasing initial search mobility and more securely launching them on employment trajectories". In that perspective education tends to insure continuity in socioeconomic inequalities from the parental home to adulthood.

Adverse health childhood conditions can play a similar role, initiating a causal chain linking early life and adulthood. Health problems can result in bad studies leading to limited professional opportunities. Or inversely the poor educational performances of children from disadvantaged households result in careers in precarious and/or risk jobs. These two pathways illustrate the debate between health selection and social causality (Palloni et al. 2009). Although the embeddedness of biological, psychological, and socioeconomic dimensions discussed in the preceding section does not help to disentangle, in the American context McLeod and Pavalko (2008) suggested that social causality is dominant in early life and that dynamic interrelationships are established subsequently. For Europe, Hoffmann et al. (2018) showed that in the transition to working age both social causality and health selection are equally weak while in the transition to retirement the social gradient in health is mainly due to social causality.

The theory of cumulative (dis)advantage is for sure the most popular in social sciences and also well-known in epidemiology. It is defined as the "systemic tendency for interindividual divergence in a given characteristic (e.g. money, health, or status) with the passage of time" (Dannefer 2003, p. 327). As an illustration, Cooper et al. (2013, p. 10) observe that adult-SEP never completely captures the association between childhood-SEP and physical capability in old age. This is why they believe that there is more than continuity in SEP and instead that accumulation processes, or additivity, have detrimental impact on functional health. Clearly, continuity or persistence is not cumulative (dis)advantage that implies a growing magnitude of the disparities (Schafer et al. 2009).

Such trends all along life can explain how, among members of the same birth cohorts, little inter-individual differences early in life expand to reach maximal amplitude among the "young old" (Dannefer 1987; Dannefer et al. 2019) (before the selection by social differential mortality changes the composition of the oldest old population). In lifespan psychology, the theory of cognitive reserve has more or less the same explanatory power since the initial consideration for education in young age has been completed with the theory of use or disuse (Richards and Deary 2013). The latter assumes that people with a high level of education (high cognitive reserve) are for the most engaged in professional activities where they will use their cognition, and consequently maintain or even increase their initial reserve. It could be intellectually demanding task but job complexity can also play this role (Kohn and Schooler 1978). Inversely those with a low level of education are more often engaged in manual repetitive works where disuse of cognition can even decrease their already lower reserve.

Aartsen et al. (2019) recently provided a strong empirical support to this vision. Based on data from the Survey of Health, Ageing and Retirement in Europe, they revealed that the relation of adverse socio-economic conditions in childhood predicting late-life cognitive outcomes is partly explained by altered cognitive reserve accumulation pathways in terms of educational and occupational attainment. Specifically, adverse childhood socioeconomic conditions lead to unfavorable education pathways. This is then continued along working life with low-skilled jobs and finally in old age resulting in lower cognitive functioning. Ihle and colleagues also demonstrated that the processes of accentuation of initial differences can be amplified by socioeconomic differences in living styles (typically the social selection of leisure activities), in social relations (typically 
friendship), or in personality traits, all elements that are more or less susceptible to enhance cognition (Ihle et al. 2015, 2018, 2019).

This model has been strengthened by research on vulnerability. Schröder-Butterfill and Marianti (2006) offered a convincing theoretical model of vulnerability demonstrating how low resources create additional exposure to risks and consequently to stress, a relation susceptible to degenerate in 'vicious circles' that could lead to psychological disorders and social exclusion (Schoon 2006; Spini et al. 2017; Oris 2017). Similarly, to associate conditions and events, Schafer et al. (2009) disentangled the onset, magnitude and duration of exposure as well as the dimensionality of adversity (specific or multiple; see also Ferraro and Schafer 2017).

Together, those theoretical bodies about accumulation and vulnerability are appealing and appear robust. However, a prominent figure of the life course studies, Glen Elder et al. (2015, p. 23) observed that "there is surprisingly little evidence for cumulative processes" and "a wide variety of model specifications remain completely untested"). This is confirmed, among others, by a systematic review of self-rated health trajectories where Cullati et al. (2014) found only limited evidence supporting the cumulative advantage theory: "gender, ethnicity, education and employment status are only moderately associated with growing influences over time, and the cumulative influences of income, occupation, age and marital status are weak."

Other empirical results have been instructive. If there are ample illustrations that a favorable starting position is a resource that produces further gains across the life course (DiPrete and Eirich 2006; Burton-Jeangros et al. 2015; Ihle et al. 2018), the opposite can be true but not always. For example, research on old age poverty in Switzerland (Oris et al. 2017) do not support the notion of an accumulation of disadvantages for people who started low, who instead of facing a descending trajectory, exhibited "status maintenance, that is, life-course continuities in social status" (Dannefer 2003, p. 329). Similarly, in an analysis of 13 European countries based on SHARE data, Wahrendorf and Blane (2015, p. 584) concluded: "Results demonstrate that advantaged circumstances during childhood are associated with lower levels of labor market disadvantage and higher quality of life in older ages. Furthermore, results of multivariate analyses support the idea that part of the association between childhood circumstances and later quality of life is explained by labor market disadvantage during adulthood". Those results suggest that the accumulation of advantages for the initially favored could coexist with "cumulative continuity" (Elder et al. 2015, p. 23) or more complicated processes mixing continuity and limited accumulation of disadvantages for those who grew in the low classes. And to increase the complexity, exceptional trajectories are not always exceptional. We noted above that low education was a strong predictor of old age poverty in Switzerland, multiplying the risk by four, but in 2011 a significant minority, about one fifth of older adults with a low human capital, were classified as wealthy (Oris et al. 2017).

To understand why (dis)advantages do not always accumulate, or not as much as the theory would predict, Schafer et al. (2009) proposed a sociological conceptualization of the psychological concept of resilience. Their starting point is a distinction between disadvantage, which is a usually objective position in an unequal distribution of resources, and "adversity which is perceived misfortune" (p. 3). An appraisal of the situation, then the absence of resignation, the belief that something can be done, are preconditions for a reaction from the individual who can mobilize personal and social resources (if available) and solicit the various forms of social benefits in his/her welfare regime (if eligible) (Henke 2016). Psychological and more recently sociological researches try to understand why some individuals are deeply and durably affected by adverse conditions or traumatic events, with long-term scarring effects (Pearlin et al. 2007), while others are "forged" since they succeed to cope, gaining self-esteem and experience that will be precious assets if life tests them again (Martucelli 2006). In-between, other individuals just maintain their life trajectory, and we must keep in mind that preserving this continuity is 
usually highly demanding for the individual (Spini et al. 2017). It is quite improbable that resilience after facing a life risk could just be a psychological predisposition randomly distributed.

Although further research is needed to understand the coping dynamics and processes, the long-term consequences in old age seem important. A prominent figure of the dialogue between sociology and psychology, Leonard Pearlin, studied the life course construction of mastery, which is the subjective evaluation by an individual of his/her capacity to control his/her life. His team identified the impact of early exposure to intractable hardships and of status maintenance, but showed that ultimately the feeling that one has kept the control of his/her past life, the appraisal (a subjective cognitive process in psychological terms) of his/her previous life course, was the most important determinant of mastery in old age (Pearlin et al. 2007). It is even more crucial if we consider the relation of mastery to selfregulation (Richards and Deary 2013), which is the core component of successful aging in Baltes view.

\subsubsection{The Government of Life Course ${ }^{3}$}

In the preceding section the search of explanation for non- or limited accumulation of disadvantages all along the life course until old age, adopted a very micro-individual perspective, although embedded in the socioeconomic structures. Time and space contexts have been considered only incidentally and deserve now to be integrated in our understanding of the life course construction of relevant resources in old age. Welfare regimes are crucial in that perspective since they heavily contributed to the institutionalization of the life courses (Kohli 2007), have at their core old age pensions and present a considerable spatial variation since they are national-state policies (Quadagno et al. 2011). This diversity is reduced thanks to the typological work of Gösta EspingAndersen (1990), which has been heavily

\footnotetext{
${ }^{3}$ We borrow this title from Leisering (2003).
}

criticized, completed (Esping-Andersen 1999) and remains highly influential, although grouping national policies is controversial (Mayer 2005). For our purposes, it makes sense to consider separately two outcomes of those regimes, wealth and health.

The fundamental rational of a pension system is to allow ending life in dignity. Some regimes have more ambition and aim to preserve the retirees' standard of living. Whatever the pensions systems offer a powerful illustration of why processes of accumulation of advantages and process of accumulation of disadvantages are not necessarily the same. Indeed, through the pensions or through a variety of social benefits, the welfare regimes offer a safety net avoiding poor people to become destitute, resulting in the below continuity that was discussed previously (Oris et al. 2017). That said, old age poverty has been seen to be less likely in social-democratic and conservative regimes than in the liberal one (Tai and Treas 2009; Dannefer et al. 2019).

These variations have several sources. A pension system is based on a life-course accumulation of contributions to constitute a capital, all along the working life, during 40-45 years. If the political logic is repartition, with the active paying for the retired, the benefits can be guaranteed. If individual capitalization logic applies, only those with a full career have a full pension. In Switzerland with a system aimed to secure basic needs in old age instituted in 1948, half of the 65 and over lived with incomes below the poverty threshold still in 1979. This figure decreased substantially in the following decades, just because more and more birth cohorts had the opportunity to accumulate during a full career (see Oris et al. 2017, and for the United-States the influential work of O'Rand 2006). Within these systems an important difference in the welfare regimes is if the state guarantees the capital, or not, when major financial crisis occurs like in 2008 (Quadagno et al. 2011). Additionally, the accumulation principle was based on the male breadwinner model, creating a structural penalty for women who have interrupted their career after marriage or motherhood, what has frequently been the case in the older birth cohorts (O'Rand 
2006). Vlachantoni (2012, p. 104) noted that "pension systems have generally been slow in mitigating 'diversion' from continuous and fulltime working lives".

The second fundamental rationale of pension systems was to allow an individual to retire without being constrained by disability. However social inequalities in health are observed everywhere and appear as a major failure of the modern welfare states (Mackenbach 2012). Bambra et al. (2010) observed educational differential in selfreported health using cross-sectional data from the European Social Survey that they stratified by birth cohorts to have a proxy of the length of exposure to various welfare regimes. They were surprised to observe larger differences among the older (who were in the 60s) instead of the opposite, and also that inequality was the smaller in the Southern and Bismarckian (conservative) regimes, not in the Scandinavian one. This was unexpected considering the large redistributions and egalitarian ethos of the latter while the Bismarckian regime is known for transferring adult socioeconomic inequalities into old age. The authors called for longitudinal analysis that was realized by Sieber et al. (2019) using SHARE data. The most robust result was that early-life conditions impact old age self-reported health, this relation being moderated by education and adult occupation in the Scandinavian regime, education in the Southern one and occupation in the Bismarckian one. Van der Linden et al. (2019) adopted the same data and methods but studied an objective measure of health, frailty. As we could expect (Mayer 2005; Raphael and Bryant 2015) the Bismarckian regime was the least able to compensate life course accumulation of disadvantages; Scandinavian but also the Southern regimes were the most efficient in that perspective. Obviously, more research on the South European policies is needed.

\subsection{Conclusions}

Changing individuals must be studied in a changing world. Ben Shlomo and Kuh (2002, p. 290)
Research on the life course construction of wealth and health in old age has flourished during the last 40 years (Burton-Jeangros et al. 2015). Considering the space available, we have not completely made justice to the many results and the knowledge acquired. Several important questions requiring more investigation have been noted across the text. The most important remaining limitation is a concentration on the early old age as a "destination" of the life course. Gerontologists have amply documented how older adults, especially the oldest old, have the ability to cope with growing health problems while maintaining their level of wellbeing. Baltes and Baltes (1991) model SOC (selection, optimization and compensation) offered a key for understanding this paradox. It is curious that this wellknown phenomenon is not really considered in the research on active aging since it reflects a disconnection between activities which are necessarily declining and stable wellbeing (Ihle et al. 2017). On one side it demonstrates that this body of literature, considering as a core principle that aging well is staying active and in good health, hides the realities of very old age. On the other side, it is also fair to recognize that empirical evidence remains scarce since maintaining a longitudinal study with sufficient sample size (implying also enough survivors or sample renewals) is highly difficult.

Recently the above mentioned LIFETRAIL project partly answered this criticism, combining SHARELIFE data and SHARE panel data to see how past life course conditions and events affect (inequalities in) health at a given point in time but also health trajectories in old age (Cheval et al. 2018, 2019; Sieber et al. 2019; Van der Linden et al. 2018). However, the panel time span is still short, only a few years, and SHARE samples are not stratified by age, with consequently a low proportion of oldest old. This research infrastructure is however by far the best we have.

Developing the approach of linking early-life and adult-life trajectories with full old age trajectories could also help to better figure out the future of aging. Indeed the many birth cohorts who will reach old and very old age in the coming decades are already living with us. Not only they 
are already born, but they have already or are in the process of being phased by the school institution, they are growing or grew in changing families and face the challenges of flexible careers in a context of global competition. In that perspective it is worth to note that the welfare regimes (also exposed to reforms) reflect political cultures that also impact educational pathways and inequalities, the regulations of the labor market or the relationships between State and the family. Concretely many studies show that the transition to adulthood could become a new sensitive period where successes or failures will have long-lasting effects (Oris 2017). Recently, Dannefer et al. (2019, p. 46) observed that more wealth inequality, more experiences of precariousness in the late baby-boomers American birth cohorts suggest more health issues when they will reach old age, considering the stability of the social gradient.

However, if there are many conditions, experiences, continuities or accumulations we could project on the future, we cannot assume that the processes, specifically the chains of risks or stress proliferation, will remain the same. Some researchers have suggested that in the "society of risk" (Giddens 1991; Beck 1992), life accidents are more frequent but as a consequence tend to become more normal, less disruptive (see Vandecasteele 2011). The future is living with us, for sure, but the future is not (completely) written.

Acknowledgments This publication benefited from the support of the Swiss National Centre of Competence in Research LIVES-Overcoming vulnerability: Life course perspectives, which is financed by the Swiss National Science Foundation (grant number: 51NF40-160590). The authors are grateful to the Swiss National Science Foundation for its financial assistance.

\section{References}

Aartsen, M. J., Cheval, B., Sieber, S., Van Der Linden, R., Gabriel, R., Courvoisier, D., et al. (2019). Advantaged socioeconomic conditions in childhood are associated with higher cognitive functioning but stronger cognitive decline in older age. Proceedings of the National Academy of Sciences, 116(12), 5478-54869.
Baeriswyl, M. (2016). Participations et rôles sociaux à l'âge de la retraite. Doctoral thesis (Socio-economics), University of Geneva.

Baltes, P. B., \& Baltes, M. M. (1991). Successful aging: Perspectives from the behavioral sciences. Cambridge: Cambridge University Press.

Bambra, C., Netuveli, G., \& Eikemo, T. A. (2010). Welfare state regime life courses: The development of western European welfare state regimes and age-related patterns of educational inequalities in selfreported health. International Journal of Health Services, 40(3), 399-420.

Barker, D. J. P. (1997). Maternal nutrition, fetal nutrition, and disease in later life. Nutrition, 13(9), 807-813.

Beck, U. (1992). Risk society: Towards a new modernity. London: Sage.

Ben-Shlomo, Y., \& Kuh, D. (2002). A life course approach to chronic disease epidemiology: Conceptual models, empirical challenges and interdisciplinary perspectives. International Journal of Epidemiology, 31, 285-291.

Bernardi, L., Huinink, J., \& Settersten, R. A. (2019). The life course cube: A tool for studying lives. Advances in Life Course Research, 41. https://doi.org/10.1016/j. alcr.2018.11.004.

Blane, D., Higgs, P., Hyde, M., \& Wiggins, R. D. (2004). Life course influence on quality of life in early old age. Social Science \& Medicine, 58, 2171-2179.

Bouchardy, C., Verkooijen, H. M., \& Fioretta, G. (2006). Social class is an important and independent prognostic factor of breast cancer mortality. International Journal of Cancer, 119, 1145-1151.

Brandt, M., Deindl, C., \& Hank, K. (2012). Tracing the origins of successful aging: The role of childhood conditions and social inequality in explaining later life health. Social Science \& Medicine, 74(9), 1418-1425.

Brückner, H., \& Mayer, K. U. (2005). De-standardization of the life course: What it might mean? And if it means anything, whether it actually took place? Advances in Life Course Research, 9, 27-53.

Bülow, M. H., \& Söderqvist, T. (2014). Successful ageing: A historical overview and critical analysis of a successful concept. Journal of Aging Studies, 31, 139-149.

Burton-Jeangros, C., Cullati, S., Sacker, A., \& Blane, D. (2015). A life course perspective on health trajectories and transitions. Heidelberg: Springer.

Cheval, B., Boisgontier, M. P., Orsholits, D., Sieber, S., Guessous, I., Rainer, G., et al. (2018). Association of early- and adult-life socioeconomic circumstances with muscle strength in older age. Age \& Ageing, 47(3), 398-407.

Cheval, B., Chabert, C., Sieber, S., Orsholits, D., Cooper, R., Guessous, I., et al. (2019). Association between adverse childhood experiences and muscle strength in older age. Gerontology. https://doi.org/10.1159/ 000494972. 
Collinet, C., \& Delalandre, M. (2014). L'injonction au bien-être dans les programmes de prévention du vieillissement. L'Année sociologique, 64(2), 445-467.

Cooper, R., Hardy, R., Sayer, A. A., \& Kuh, D. (2013). A life course approach to physical capability. In D. Kuh et al. (Eds.), A life course approach to healthy ageing. Oxford: Oxford University Press.

Cullati, S., Rousseaux, E., Gabadinho, A., Courvoisier, D. S., \& Burton-Jeangros, C. (2014). Factors of change and cumulative factors in self-rated health trajectories: A systematic review. Advances in Life Course Research, 19, 14-27.

Cullati, S., Kliegel, M., \& Widmer, E. (2018). Development of reserves over the life course and onset of vulnerabilities in old age. Nature Human Behaviour, 2(8), 551-558.

Dannefer, D. (1987). Aging as Intracohort differentiation: Accentuation, the Matthew effect, and the life course. Sociological Forum, 2(2), 211-236.

Dannefer, D. (2003). Cumulative advantage/disadvantage and the life course: Cross-fertilizing age and social science theory. Journals of Gerontology Series B: Psychological Sciences and Social Sciences, 58(6), 327-337.

Dannefer, D., Han, C., \& Kelley, M. (2019). Beyond the "have" and have nots". A sociological look at inequality and cumulative dis/advantage over the life course. Generations, 42(4), 42-49.

DiPrete, T. A., \& Eirich, G. M. (2006). Cumulative advantage as a mechanism for inequality: A review of theoretical and empirical developments. Annual Review of Sociology, 32, 271-297.

Elder, G. H., Jr., Shanahan, M. J., \& Jennings, J. A. (2015). Human development in time and place. In R. M. Lerhner (Ed.), Handbook of child psychology and developmental science (pp. 6-54). Hoboken, NJ: Wiley.

Elias, N. (1991). The society of individuals. Oxford: Blackwell.

Esping-Andersen, G. (1990). The three worlds of welfare capitalism. Princeton, NJ: Princeton University Press.

Esping-Andersen, G. (1999). Social foundations of postindustrial economies. Oxford: Oxford University Press.

Ferraro, K., \& Schafer, M. H. (2017). Visions of the life course: Risks, resources, and vulnerability. Research in Human Development, 14(1), 88-93.

Gale, C., Deary, I., \& Stafford, M. (2013). A life course approach to psychological and social wellbeing. In D. Kuh et al. (Eds.), A life course approach to healthy ageing. Oxford: Oxford University Press.

Galobardes, B., Lynch, J., \& Davey Smith, G. (2007). Measuring socioeconomic position in health research. British Medical Bulletin, 81-82, 21-37.

Giddens, A. (1991). Modernity and self-identity. Self and society in the late modern age. Cambridge: Polity.

Haas, S. (2008). Trajectories of functional health: The 'long arm' of childhood health and socioeconomic factors. Social Science \& Medicine, 66(4), 849-861.
Hatch, S., Huppert, F. A., Abbott, R., Croudace, T., Ploubidis, G., Wadsworth, S., et al. (2007). A life course approach to well-being. In J. Haworth \& G. Hart (Eds.), Well-being (pp. 187-204). London: Palgrave Macmillan.

Henke, J. (2016). Revisiting economic vulnerability among Swiss pensioners: Low income, difficulties in making ends meet and financial worry. Springer.

Hoffmann, R., Krôger, H., \& Pakpahan, E. (2018). Pathways between socioeconomic status and health: Does health selection or social causation dominate in Europe? Advances in Life Course Research, 36, 23-36.

Honneth, A. (2004). Organized self-realization some paradoxes of individualization. European Journal of Social Theory, 7(4), 463-478.

Ihle, A., Oris, M., Fagot, D., Baeriswyl, M., Guichard, E., \& Kliegel, M. (2015). The association of leisure activities in middle adulthood with cognitive performance in old age: The moderating role of educational level. Gerontology, 61(6), 543-550.

Ihle, A., Gouveia, É., Gouveia, B., Gabriel, R., Oris, M., Fagot, D., et al. (2017). The role of leisure activities in mediating the relationship between physical health and well-being: Differential pattern in old and very old age. Gerontology, 63(6), 560-571.

Ihle, A., Oris, M., Fagot, D., Chicherio, C., van der Linden, R., Sauter, J., et al. (2018). The association of educational attainment and cognitive level of job with old age verbal ability and processing speed: The mediating role of chronic diseases. Applied Neuropsychology: Adult, 25(4), 356-362.

Ihle, A., Zuber, S., Gouveia, E., Gouveia, B., Mella, N., Desrichard, O., et al. (2019). Cognitive reserve mediates the relation between openness to experience and smaller decline in executive functioning. Dementia and Geriatric Cognitive Disorders. https://doi.org/10. 1159/000501822.

Janssen, F., \& Van Poppel, F. (2015). The adoption of smoking and its effect on the mortality gender gap in Netherlands: A historical perspective. BioMed Research International, 2015, 370274, 12 p.

Jivraj, S., \& Nazroo, J. (2014). Determinants of socioeconomic inequalities in subjective well-being in later life: A cross-country comparison in England and the USA. Quality of Life Research, 23(9), 2545-2558.

Katz, S. (1996). Disciplining old age. The formation of gerontological knowledge. Charlottesville: University Press of Virginia.

Keister, L. A., \& Southgate, D. E. (2012). Inequality: A contemporary approach to race, class and gender. Cambridge: Cambridge University Press.

Kelly-Irving, M., Mabile, L., Grosclaude, P., Lang, T., \& Delpierre, C. (2013). The embodiment of adverse childhood experiences and cancer development: Potential biological mechanisms and pathways across the life course. International Journal of Public Health, 58(1), 3-11. 
Kohli, M. (2007). The institutionalization of the life course: Looking back to look ahead. Research in Human Development, 4, 253-271.

Kohn, M. L., \& Schooler, C. (1978). The reciprocal effects of the substantive complexity of work and Intellectual flexibility: A longitudinal assessment. American Journal of Sociology, 84(1), 24-52.

Kuh, D. (2007). A life course approach to healthy aging, frailty, and capability. Journal of Gerontology Medical Science, 62A(7), 717-721.

Landös, A., von Arx, M., Cheval, B., Sieber, S., Kliegel, M., Gabriel, R., et al. (2018). Childhood socioeconomic circumstances and disability trajectories in older men and women: A European cohort study. European Journal of Public Health, 29(1), 50-58.

Lantz, P. M., House, J. S., Mero, R. P., \& Williams, D. R. (2005). Stress, life events, and socioeconomic disparities in health: Results from the Americans' changing lives study. Journal of Health and Social Behavior, 46(3), 274-288.

Leisering, L. (2003). Government and the life course. In J. T. Mortimer \& M. J. Shanahan (Eds.), Handbook of the life course (pp. 205-225). New York: Springer.

Levy, R., \& Bühlmann, F. (2016). Towards a sociostructural framework for life course analysis. Advances in Life Course Research, 30, 30-42.

Mackenbach, J. P. (2012). The persistence of health inequalities in modern welfare states: The explanation of a paradox. Social Science \& Medicine, 75(4), 761-769.

Martucelli, D. (2006). Forgé par l'épreuve. L'individu dans la France contemporaine. Paris: A. Colin.

Mayer, K. U. (2004). Whose lives? How history, societies and institutions define and shape the life courses. Research in Human Development, 1, 161-187.

Mayer, K. U. (2005). Life courses and life chances in a comparative perspective. In S. Svallfors (Ed.), Analyzing inequality: Life chances and social mobility in comparative perspective (pp. 17-55). Stanford: Stanford University Press.

McEniry, M. (2013). Early-life conditions and older adult health in low- and middle income countries: A review. Journal of Developmental Origins of Health and Disease, 4(1), 10-29.

McLeod, J. D., \& Pavalko, E. K. (2008). From selection effects to reciprocal processes: What does attention to the life course offer? Advances in Life Course Research, 13, 75-104.

Mendes, F. (2013). Active ageing: A right or a duty? Health Sociology Review, 22(2), 174-185.

O'Rand, A. M. (2006). Stratification and the life course: Life course capital, life course risks, and social inequality. In R. Binstock, L. K. George, S. J. Cutler, J. Hendricks, \& J. H. Schulz (Eds.), Handbook of aging and the social sciences (6th ed., pp. 145-162). Burlington: Academic.

Oris, M. (2017). Vulnerability. A life course perspective. Revue de Droit Comparé du Travail et de la Sécurité sociale, 4, 6-17.
Oris, M., Dubert, I., \& Viret, J. L. (2015). Vieillir. Les apports de la démographie historique et de l'histoire de la famille. Annales de Démographie Historique, 1, 201-229.

Oris, M., Gabriel, R., Ritschard, G., \& Kliegel, M. (2017). Long lives and old age poverty. Social stratification and life course institutionalization in Switzerland. Research in Human Development, 14(1), 68-87.

Pakpahan, E., Hoffmann, R., \& Kröger, H. (2017). The long arm of childhood circumstances on health in old age: Evidence from SHARELIFE. Advances in Life Course Research, 31, 1-10.

Palloni, A., Milesi, C., White, R. G., \& Turner, A. (2009). Early childhood health, reproduction of economic inequalities and the persistence of health and mortality differentials. Social Science \& Medicine, 68, 1574-1582.

Pearlin, L., Schieman, S., Fazio, E., \& Meersman, S. (2005). Stress, health and the life course: Some conceptual perspectives. Journal of Health and Social Behavior, 46(2), 205-219.

Pearlin, L., Nguyen, K. B., Schieman, S., \& Milkie, M. (2007). The life-course origins of mastery among older people. Journal of Health and Social Behaviour, 48, 164-179.

Pinquart, M., \& Sorensen, S. (2000). Influences of socioeconomic status, social network, and competence on subjective well-being in later life: A met-analysis. Psychology and Aging, 15(2), 187-224.

Quadagno, J., Kail, B. L., \& Shekha, K. R. (2011). Welfare states: Protecting or risking old age? In R. A. Settersten \& J. L. Angel (Eds.), Handbook of sociology of aging (pp. 321-332). New York: Springer.

Raphael, D., \& Bryant, T. (2015). Power, intersectionality and the life course: Identifying the political and economic structures of welfare states that support or threaten health. Social Theory and Health, 1-22.

Richards, M., \& Deary, I. (2013). A life course approach to cognitive capability. In D. Kuh et al. (Eds.), A life course approach to healthy ageing. Oxford: Oxford University Press.

Rowe, J. W., \& Kahn, R. L. (1987). Human aging: Usual and successful. Science, 237, 143-149.

SAPEA, Science Advice for Policy by European Academies. (2019). Transforming the future of ageing. Berlin: SAPEA.

Schafer, M. H., Shippie, T., \& Ferraro, K. F. (2009). When does disadvantage not accumulate? Toward a sociological conceptualization of resilience. Swiss Journal of Sociology, 35(2), 231-251.

Schoon, I. (2006). Selection, causation and cumulative risk effects. In I. Schoon (Ed.), Risk and resilience: Adaptations in changing times (pp. 57-73). Cambridge: Cambridge University Press.

Schröder-Butterfill, E., \& Marianti, R. (2006). A framework for understanding old-age vulnerabilities. Ageing \& Society, 26(1), 9-35.

Sen, A. (1999). Development as freedom. New York: Alfred Knopf. 
Settersten, R. (Ed.). (2018). Invitation to the life course: Toward new understandings of later life. London: Routledge.

Sieber, S., Cheval, B., Orsholits, D., Van der Linden, B. W. A., Guessous, I., Gabriel, R., et al. (2019). Welfare regimes modify the association of disadvantaged adult-life socioeconomic circumstances with self-rated health in old age. International Journal of Epidemiology, 48(4), 1352-1366.

Spini, D., Bernardi, L., \& Oris, M. (2017). Towards a life course framework for studying vulnerability. Research in Human Development, 14, 5-24.

Stern, Y. (2002). What is cognitive reserve? Theory and research application of the reserve concept. Journal of the International Neuropsychological Society, 8, 448-460.

Tai, T., \& Treas, J. (2009). Does household composition explain welfare regime poverty risks for older adults and other household members. Journal of Gerontology: Social Sciences, 64B(6), 777-787.

Van der Linden, B. W. A., Courvoisier, D., Cheval, B., Sieber, S., Bracke, P., Guessous, I., et al. (2018). Effect of childhood socioeconomic conditions on cancer onset in later life: An ambidirectional cohort study. International Journal of Public Health, 63(7), 799-810.

Van der Linden, B. W., Sieber, S., Cheval, B., Orsholits, D., Guessous, I., Gabriel, R., et al. (2019). Life-course circumstances and frailty in old age within different European welfare regimes: A longitudinal study with SHARE. The Journals of Gerontology, Series B:
Psychological Sciences and Social Sciences. https:// doi.org/10.1093/geronb/gbz140.

Van Dyk, S. (2014). The appraisal of difference: Critical gerontology and the active-ageing paradigm. Journal of Aging Studies, 31, 93-103.

Vandecasteele, L. (2011). Life course risks or cumulative disadvantage? The structuring effect of social stratification determinants and life course events on poverty transitions in Europe. European Sociological Review, 27(2), 246-263.

Vanhoutte, B., \& Nazroo, J. (2016). Life course pathways to later life wellbeing: A comparative study of the role of socio-economic position in England and the U.S. Population Ageing, 9, 157-177.

Vlachantoni, A. (2012). Financial inequality and gender in older people. Maturitas, 72, 104-107.

Wahrendorf, M., \& Blane, D. (2015). Does labour market disadvantage help to explain why childhood circumstances are related to quality of life at older ages? Results from SHARE. Aging \& Mental Health, 19(7), 584-594.

Wilson, R. S., Krueger, K. R., Arnold, S. E., Barnes, L. L., de Leon, C. F. M., Bienias, L., et al. (2006). Childhood adversity and psychosocial adjustment in old age. American Journal of Geriatric Psychiatry, 14, 307-315.

World Health Organisation. (2002). Active ageing. A policy framework. A contribution of the World Health Organisation to the Second United Nations World Assembly on Ageing, Madrid.

Open Access This chapter is licensed under the terms of the Creative Commons Attribution 4.0 International License (http://creativecommons.org/licenses/by/4.0/), which permits use, sharing, adaptation, distribution and reproduction in any medium or format, as long as you give appropriate credit to the original author(s) and the source, provide a link to the Creative Commons license and indicate if changes were made.

The images or other third party material in this chapter are included in the chapter's Creative Commons license, unless indicated otherwise in a credit line to the material. If material is not included in the chapter's Creative Commons license and your intended use is not permitted by statutory regulation or exceeds the permitted use, you will need to obtain permission directly from the copyright holder. 